\title{
La hégira Touraine y el perpetuo ocaso de los movimientos sociales en América Latina
}

Miguel Urrutia Doctor $($ en Socilogía

Aunque Touraine ha sostenido que el sujeto se constituye colectivamente, la producción última del sentido la hace residir en entidades de conciencia identificadas consigo mismas, es decir, en individuos; de este modo, se ha conectado con cierto izquierdismo latinoamericano y su invocación a "sujetos de derecho" titulares de una "soberanía" que, en última instancia, supone el "control consciente sobre un sí mismo". Así, los axiomas de la política liberal individualista pasan a constituir el fondo constante sobre el cual se efectúan hasta los cambios sociales más profundos.

Palabras clave izquierda / derechismo / accionalismo / política / imperio / movimientos sociales. 
Abstract

Although Touraine has maintained that the subject is constituted collectively, the last production of sense resides in identified organizations of conscience within themselves, that is to say, in individuals; this way, it has connected with certain Latin American leftist orientation and its invocation to " subjects of right" entitled to a "sovereignty" that, in last instance, supposes the "conscientious control on itself". Thus, the axioms of the individualistic liberal policy happen to constitute the constant bottom on which take place the deepest social changes.

Key words

Left / right / factionalism / politics / empire / social movements 


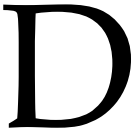

el modo más general, la política comprende el conjunto de praxis con las que se gestiona colectivamente el poder; ${ }^{1}$ sin embargo, la ciencia que ha reclamado a la política como su objeto propio, lo ha hecho acotando esta generalidad en la categoría de "sistema político" propuesta hace más de medio siglo por el estadounidense David Easton. ${ }^{2}$ La "política" ha quedado así muchas veces reducida a las alternativas de la administración estatal, a los actos de gobierno y, sobre todo, a los problemas corporativos en la formación de la ley y sus instituciones. Cierta sociología, de gran influencia en América Latina, parece haber aceptado esta reducción conceptual de la política, al imponerla -en los momentos cumbre de sus análisis- como el marco en el cual las acciones colectivas alcanzarían sus sentidos históricos más trascendentes.

“Los chilenos y yo defendimos mucho el tema de los movimientos urbanos en Buenos Aires, en Santiago, en Sao Paulo o después del terremoto de México en 1985. Pero Fernando Enrique Cardoso y, sobre todo su esposa Ruth, respondían: esa es una ilusión. Si los movimientos urbanos reemplazan la acción política, se creará un nuevo clientelismo, porque el grado de integración de la sociedad no es suficiente para que se

1 En la visión de Foucault, toda acción mediante la cual una voluntad busca determinar conductas ajenas configura una relación de poder que es intrínsecamente política: Foucault M. Microfísica del poder La Piqueta, Madrid, 1992.

2 Easton, David The Political System: An Inquiry into the State of Political Science Alfred A. Knopf, N.Y., 1953 
formen movimientos sociales. Prioridad a la política. Hay que apoyarse menos en los curas [de la iglesia popular] y más en los senadores y los diputados: hay que repolitizar. Ruth Cardoso, históricamente hablando, ha tenido razón. La reconstrucción política ha jugado un rol más durable que los movimientos, los que a menudo han zozobrado en un radicalismo ciego". ${ }^{3}$

En efecto; a pesar de haber criticado el formalismo democrático de liberales como Norberto Bobbio ${ }^{4}$ y de haber apoyado resueltamente al zapatismo chiapaneco, ${ }^{5}$ Alain Touraine ha cultivado largamente un régimen enunciativo $^{6}$ de cuyas cauciones moderadoras se ha abrevado el conformismo y la autorreferencialidad de las clases políticoparlamentarias ${ }^{7}$ de América Latina que desde mediados de los ochenta avanzaron "hacia una solución de compromiso, en la cual el sujeto social colectivo es reabsorbido en la ciudadanía individual. Por una inversión de las significaciones, el sujeto social colectivo es referido al ámbito privado, mientras el sujeto político individual es referido al ámbito público. No escapa al análisis el comprender que las tendencias recién señaladas concuerdan con la reconstitución de la 'normalidad institucional' (...) Pero tal constatación no elimina el planteamiento del problema ni exime del estudio acerca del curso real que tomen esas tendencias (...)." 8

3 Touraine, Alain \& Fahrad Khosrokhavar La recherche de soi. Dialogue sur le Sujet Fayard, Paris, 2000. Traducción no autorizada de un párrafo correspondiente a la página 283 (negrillas y subrayados también nuestros)

4 Touraine, Alain Qu'est-ce que la democratie? Fayard, Paris, 1994.

5 El zapatismo constituye, para nosotros, el paradigma de las acciones colectivas cuya politicidad excede los márgenes que Touraine considera como consubstanciales a todo movimiento social.

6 Dado que este artículo forma parte de un trabajo más extenso en el que se abordan algunos aspectos del análisis del discurso en Foucault, simplificaremos por ahora la noción de régimen enunciativo a la idea de un perfil.

7 Aunque el concepto "clase política" fue un componente del pro-fascismo de Gaetano Mosca, en la actualidad, se utiliza para designar al conjunto de sujetos ocupados en cargos de elección pública o designados por éstos y que han desarrollado, de hecho, comportamientos colectivos propios de una corporación profesional. Ya que, desde una perspectiva marxiana, toda "clase" es intrínsecamente "política", por nuestra parte sólo hemos agregado la palabra "parlamentaria” para distinguir este caso específico.

8 Baño, Rodrigo Lo social y lo político, un dilema clave del movimiento popular, FLACSO-Ediciones Ainavillo, Santiago de Chile, 1985, p. 185. Nuestro trabajo se sitúa en importante medida en las huellas y los problemas sugeridos por Baño. 


\section{II}

Todo parece indicar(nos) que, habiéndolo conocido en Harvard, Touraine decidió convertirse en la 'izquierda no estalinista' de Talcott Parsons. Frente al "acto común unitario", concebido por Parsons como la mínima unidad de análisis para reconocer la propiedad desviada o integradora de las acciones sociales, Touraine propuso su concepto de "acción" como la puesta en obra del atributo creativo del ser humano, el que se expresaría colectivamente en el trabajo. ${ }^{9}$ La acción social para Touraine no estaría entonces determinada por el ajuste lineal entre medios y fines. Ambos podrían resultar incluso reinventados por el sujeto humano ejerciendo su margen de libertad en un movimiento conflictivo perpetuo que produciría a la sociedad desde sí misma y no desde una especialización de roles ajustados a supuestos valores universales; así, el actor no sería "aquel que obra con arreglo al lugar que ocupa en la organización social, sino aquel que modifica el ambiente material y sobre todo social en el cual está colocado al transformar la división del trabajo, los criterios de decisión, las relaciones de dominación o las orientaciones culturales"10.

Touraine ha planteado que, en todo tiempo y lugar, las sociedades se constituirían en torno a un "modelo cultural" en el que se harían una representación de su historicidad, es decir, de su capacidad para actuar creativamente sobre sí misma, y no sólo reproducirse funcionalmente. El modelo cultural se transformaría en praxis concreta a través de un "Sistema de Acción Histórica" consistente en un "conjunto de orientaciones socio-culturales que rigen las formas de trabajo"11 dando origen a un "modelo ético", a un "modelo de conocimiento", y a un "modelo de acumulación". El sistema de acción histórica constituiría el tinglado de un "conflicto

9 Touraine, Alain Sociología de la acción Ariel, Madrid, 1969.

10 Touraine, Alain Crítica de la modernidad Fondo de Cultura Económica, México,1994, p. 208

11 Touraine, Alain Producción de la sociedad UNAM-IIS-IFAL, México, 1995, p. 65 
social central" en que una "clase popular" disputaría el control a una "clase superior", proceso en el cual la primera podría asumir los caracteres de "dominada" o "contestataria", mientras la segunda de "dominante" o "dirigente"; el tipo de conflicto, que, a la vez animaría y prepararía el desborde del sistema de acción histórica, se definiría en acuerdo con las cuatro combinaciones posibles entre clases populares y superiores. ${ }^{12}$

Las acciones colectivas que expresasen el conflicto central de clase se reconocerían por poseer una "identidad" que devolvería al grupo una imagen cohesionada de sí, transformándolo en un actor colectivo que desarrollaría su "oposición" a un adversario, basado en un proyecto que implicaría a la sociedad en su "totalidad", alcanzando, entonces, el estatuto de "movimiento social". Así Touraine distingue el movimiento social de la clase superior y el "movimiento social popular"; cada cual compuesto por movimientos sociales específicos. En la sociedad industrial, cuya caída habría comenzado alrededor de la sexta década del siglo XX, el movimiento obrero habría expresado la centralidad del conflicto desde la clase popular, mientras que, en la "sociedad post-industrial", los movimientos sociales responderían a un nuevo modelo cultural que estaría reemplazando la racionalidad del progreso tecnológico por la realización del individuo como sujeto activo de su propia existencia.

“(...) la reivindicación era, en otro tiempo, la del trabajador productivo creador contra el peso y la inmovilidad del orden, del poder y de la herencia. Hoy, frente al movimiento dominado por los aparatos y la clase dirigente, la reivindicación es la del ser, la autonomía de su experiencia y su expresión, y su capacidad de administrar y controlar los cambios que le afectan". ${ }^{13}$ 


\section{III}

Todo lo anterior explicaría que, en el ámbito de una sociedad post-industrial o "programada", la acción colectiva se hubiese desplazado hacia los temas personales y morales, los que, más allá de formas organizadas de movilización, se expresarían en preferencias, opiniones y actitudes de la vida cotidiana. Por su parte, el concepto de sujeto correspondería a "la voluntad de un individuo de obrar y ser reconocido como actor", ${ }_{1}^{14}$ por lo que sólo podría existir como movimiento social en tanto esfuerzo"de un actor colectivo [por] adueñarse de los valores, de las orientaciones culturales de una sociedad oponiéndose a la acción de un adversario con el que está vinculado por relaciones de poder". ${ }^{15}$ En ningún caso, para Touraine, el sujeto se realizaría en la dirección social de un centramiento identitario; de hecho, el autor ha promovido más recientemente lo que denomina un "doble apartamiento" para el sujeto, el que implicaría alejarse tanto de las identidades comunitarias cerradas (caso de los nacionalismos), como del individualismo consumista y mercantilizante. Para Touraine, el sujeto no es entonces una realidad innata, sino una condición a la que el individuo puede acceder mediante un especial acto de conciencia volitiva "la subjetivación es la penetración del sujeto en el individuo y por consiguiente la transformación -parcial- del individuo en sujeto"; 16 donde la conciencia no queda tan simplemente referida a sí misma, sino a reconocer en las conciencias "otras" un recíproco estatuto de liberación
“(...) la definición [de sujeto] sólo puede ser negati- va y adquiere un contenido únicamente a través del reconocimiento del Otro como Sujeto y la adhesión a unas reglas jurídicas y políticas de respeto por sí mismo y por el otro como sujetos. El sujeto no puede existir más que al apartarse de su propia conciencia,

14 Touraine, Alain Crítica de la ... p. 207

15 Touraine, Alain Crítica de la ... p. 236

16 Touraine, Alain Crítica de la ... p. 209 
así como de las fuerzas que percibe [erróneamente] como exteriores". ${ }^{17}$

El individuo, como existencia concreta, podría dar lugar a un sujeto sólo cuando, en virtud de su relación con otros (compañeros y/o adversarios), formase un nuevo tipo de conciencia referida ya no a un centro idéntico a sí mismo, sino a su capacidad transformadora del mundo; sin embargo, y como puede apreciarse, en el principio del sujeto, seguiría estando la conciencia individual. Efectivamente, a pesar de su participación en la protesta ritual contra los abusos de la razón moderna ("yo pienso"), Touraine jamás desconfía del más fundamental principio moderno que supone un núcleo íntimo y primigenio para el "sí mismo" ("Y음 existo"), al contrario, lo toma por condición para la constitución socio-relacional del ser humano.

Lo que no puede ser aceptado por sociólogos 'antiestructuralistas' como Touraine, y de otro modo tampoco por Giddens, es la acechanza de un concepto de sujeto "absolutamente histórico"18; es decir, el sujeto como una materia formada sin más atributos que aquellos temporalmente derivados de las confrontaciones de fuerzas en las que contingentemente participa (por cierto que el estructuralismo contribuyó a tal concepción de sujeto; sin embargo, su desconsideración cuasi absoluta por la historia señaló un vacío teórico tan enorme, que tampoco pudo ser llenado por la historicidad metafísicamente escamoteada de los humanismos ${ }^{19}$ ). Pero, un sujeto de este tipo, portador de todos los nombres de la historia, es, para la sociología humanista, un antisujeto, y por lo tanto, la entrada en un

17 Touraine, Alain ¿Podremos vivir juntos? Fondo de Cultura Económica, México, 1996, p. 83

18 Usamos las tres palabras en este orden con el fin de distinguir el concepto de la figura archisuperada del "sujeto histórico absoluto".

19 El grave error estructuralista del que se han alimentado las regresiones humanistas consistió en presuponer la exterioridad objetiva y atemporal de las fuerzas que cruzan las subjetividades. No obstante, se trató de un riguroso esfuerzo por desentrampar el análisis de las categorías metafísicas que habían fundado aquel sujeto ontologizado como "humano". 
conservadurismo posmoderno, ya que afirmar que el sujeto no tiene su centro en una fuerza diferenciable de todas las otras que operan en el universo, equivaldría a decir que el sujeto es todo y, por tanto -desde una lógica aristotélico tomista; nada, o, al menos, nada que pueda ser 'científicamente nombrado'.

Resulta entonces claro que, para Touraine, el individuo es la sustancia que, en medio de la contingencia, retiene naturalmente una básica identidad de sí para -sólo desde tal posición- abrirse al "ser" de las diferencias; empero, al arrancar este juego de relaciones de su pretendida evidencia, aparece la posibilidad cierta de un sujeto universalmente indiferenciado, cuya implicación conflictiva deriva de saberes formados en la experiencia inmediata del mundo.

Por ejemplo, desde el punto de vista recién expuesto, los jóvenes que se abstienen de votar en todas las democracias occidentales no devendrán sujetos cuando propongan conciente y colectivamente una nueva forma de participación política (donde analistas profesionales juzgarían qué es "lo conciente", "lo colectivo", "lo participativo", y sobre todo, "lo político"); como tampoco puede imputárseles el carácter de "semillas" (portadores inconscientes) de una nueva política; simplemente son sujetos ya en este mismo minuto, incluso al ser traspasados por esas fuerzas que los teóricos liberales llaman desencanto o apatía. Son sujetos porque su estar en el mundo permite verificar la existencia de una fuerza que pasa a través de ellos adquiriendo vecciones siempre imprevisibles para las voluntades formadas al interior de un orden ya dado. Son sujetos porque son punto de fuerza que la dominación social sólo puede recuperar a posteriori, sujetos insujetados porque en ellos se condensan tales cantidades de fuerzas que la conciencia individual no alcanza a hacerse más que un pálido dibujo de su potencia.

Un sujeto tempoespacialmente destilado por la colisión de fuerzas universales, ciertamente no puede arribar 
a la condición de "dueño de sí mismo". Por tanto, sólo es concebible en el marco de luchas -de suyo radicalescontra toda forma de propiedad y contra toda praxis de apropiación sobre aquello que se produce en el universo de la colectividad. Contra esto, es que Touraine recoloca una concepción centradora del sujeto; fuerte en la única medida en que consiguiese dar "consigo mismo", curando de paso los desgarramientos de una modernidad urgida de nuevos equilibrios. Touraine llama a salvar al sujeto de la inanición histórica para entregarle un protagonismo a la medida de su sistema ideacional, allí donde resulta impensable alguna forma de lucha de los oprimidos que no sea a partir de su sujetación a un 'yo' ontológico. ${ }^{20}$

El cambio sólo es concebible para Touraine dentro de la coreografía que él ha definido: siempre habrá sujetos más o menos dominadores y sujetos más o menos dominados, cambiando continuamente sus correlaciones de fuerza hasta desgastar y provocar la mutación en bloque de un modelo cultural metaconsensuado, ${ }^{21}$ dando origen a un "nuevo" sistema de acción histórica en que habrá por siempre un sistema político más o menos diferenciado, un estado, un gobierno, etc. (es por eso que, cuando estos referentes han comenzado a ser puestos en cuestión, Touraine interpreta que es la convivencia social misma la que se encuentra en peligro de desaparecer); cada uno con el margen de acción que le permite su propio y 'libre' virtuosismo en la ejecución de la pieza coreográfica puesta en evidencia por el sociólogo que únicamente interviene la acción invitando al actor hasta su observatorio.

Tras la proclamación de un cambio completo en la sociedad, como si de un gran bloque geológico se tratase, Touraine oscurece el modo en que transformaciones parciales -micropolíticas- afectan los términos de base de las relaciones de poder, dejando, al menos, la posibilidad de

20 En tanto, el yo psicológico convencional es criticado por Touraine.

21 Seguimos aquí el análisis de Baño, Rodrigo op. cit. 
que el conflicto entre dominadores y dominados estuviese ahora mismo deviniendo en algo indescriptible desde la lógica de los sistemas de acción histórica. Con todo esto, Touraine se abona el terreno para salidas y conclusiones políticas recurrentemente conservadoras, como ocurrió con sus reticencias frente a la innovadora huelga francesa de $1995,{ }^{22}$ con su "gesto comprensivo" ante la 'bajada' de los movimientos populares en la negociación política de las transiciones democráticas latinoamericanas, o con su idea de una actualidad caracterizada por el agotamiento de la normatividad social que -según el autor- podría llevarnos a la imposibilidad de "vivre ensemble". Touraine no cesa de evaluar las transformadas relaciones de poder con las categorías que los poderes dominantes han producido antes de cada transformación. Se apresura, por ejemplo, a decir que los oprimidos de la sociedad post-industrial luchan por algo concretamente distinto a aquello por lo que lucharon en la sociedad industrial, pero su teoría no está disponible para evaluar cuánto de lo nuevo en esas luchas se ubica no en sus finalidades concientes, sino en la multiplicidad des-ordenada de unos medios políticamente 'impensados' por la modernidad.

El problema estriba en que, al concebir el cambio social adosado al movimiento de un gran bloque histórico -de la "Sociedad X" a la "Sociedad Y" 23 -, Touraine define el fondo invariable sobre el cual ocurre ese cambio; del mismo modo, la posibilidad de alterar ese fondo se convierte en el vertedero de sus más honestos y sentidos temores (para América Latina: totalitarismos del tipo cubano y mesianismos del tipo guevarista). Analizar el cambio como el paso de la "Sociedad X" a la "Sociedad $Y$ " no es, por otra parte, una condición para realizar la saludable distinción entre

22 Touraine, Alain et al. Le grand refus, réflexion sur la grève de décembre 1995, Fayard, París, 1996.

23 Giddens ya hizo una crítica contundente a esta perspectiva, y, aunque su trabajo ha circulado por el mismo carril político que el de Touraine, se ha mantenido consistente frente a la tentación de proclamar un cambio epocal completo. 
un "sujeto de la emancipación" (sujetado metafísicamente a una utopía mesiánica) y un "sujeto emancipándose". Compartimos el rechazo a la idea de emancipación como totalidad social, o la idea de "una" "sociedad emancipada"; pero, concebir las luchas sociales como búsqueda constante de más y mejores 'estados' de emancipación no implica condenar estas experiencias a los marcos prodigados por las sociedades " $\mathrm{X}$ ", " $\mathrm{Y}$ " o " $\mathrm{Z}$ ", especialmente si lo que éstas mantienen en común es la expoliación económica del trabajo. Para Touraine, el cese de la explotación no sería más que un componente ideológico en el imaginario de "totalidad" enarbolado por todo movimiento social, un horizonte utópico que, aunque propiamente irrealizable, contribuiría al jalonamiento constante del "sujeto emancipándose", a condición de que este elemento no se 'totalice sobre la totalidad', caso, en el cual, Touraine advertiría que se ha atravesado hacia el campo de la lucha de clases, donde se intentaría imponer ideológicamente el antagonismo entre clases superiores y populares.

Las acciones colectivas antagónicas son sobreentendidas por Touraine como rupturas al interior del conflicto central, genuinas defecciones en la dialéctica de la emancipación permanente que crearían un vacío en las relaciones de poder, abriendo espacio para sobrepujamientos y suplantaciones operadas por vanguardias historicistas que intentarían expandir el antagonismo a guisa de pura necesidad y teleología histórica, negando así el principio mismo de la acción creativa y recayendo, por tanto, en nuevos funcionalismos, esta vez, revolucionaristas ${ }^{24}$.

\section{IV}

Ocurre, en efecto, que las autodenominadas vanguardias revolucionarias suelen darse la mano con su fustigador

24 Ver el prefacio de la edición ya citada de Producción de la sociedad. 
Touraine, al suponer que el antagonismo consiste fundamentalmente en la negación de un contrario, y, en el caso de las vanguardias leninistas, suponer que el antagonismo consiste en la negación de la explotación, la que, a su vez, ya implica una negación de lo obrado por el trabajo; de tal manera que este último no podría constituirse políticamente sino como negación de su negación. ${ }^{25}$ Pero, acuerdo con lo que viene fundamentando la historiografía inaugurada en Chile por Gabriel Salazar, el sujeto absolutamente histórico no antagoniza desde la autoconciencia de su explotación, sino desde la afirmación de su contingencia particular e irreductible.

“(...) el pueblo que hace historia no consiste sólo en los sin-propiedad atacando a los con-propiedad, los sin-Estado utilizando el Estado de otros, los que son nada destruyendo [a] los que son todo. Porque el movimiento es una potencia y la potencia es en sí una afirmación (...) el pueblo no está forzado a ocupar sólo los espacios (...) apropiados de su enemigo, sino, fundamentalmente, los espacios libres e inalienables del pueblo mismo. Es decir, no debe trabajar TANTO o SÓLO la idea de expropiar al enemigo, COMO el desarrollo de su propia afirmación como pueblo". ${ }^{26}$ Touraine también atribuye importancia a las prácticas de autogestión por parte del movimiento popular post-industrial, ${ }^{27}$ pero cuidando sobre todo de no afectar la moderna oposición social / político; particularmente en sus análisis de América Latina, Touraine ha demostrado que, promover la autogestión en los movimientos sociales, constituye sólo un medio para componer un sistema de cambio que mantiene compartimentada a la política en un sub-

25 Seguimos aquí GS-AR Notas acerca del nuevo proyecto histórico del pueblo de Chile Mimeo, Hull, Inglaterra, 1981.

26 Ibídem, p. 42

27 Touraine, Alain Producción de la Sociedad (1995). 
sistema especializado o diferenciado de los saberes que construyen la sociabilidad de base. ${ }^{28}$

Sin embargo, cuando una multiplicidad de sujetos explotados hace una parte de la historia (por ínfima que ella sea) como conjunto de experiencias productivas propias y anteriores a ser separado de ellas por la "abstracción material" del valor de cambio, señala, en este mismo acto, la presencia de un antagonismo donde lo fundamental no consiste en negar a su adversario pretendiendo privarlo de los medios con los que éste se apropia de su trabajo, sino más simplemente en performar políticamente el carácter colectivo -inadjudicable individualmente- de la producción de valores, lo que hace crujir el touraineano orden de los sistemas de acción histórica. Podría haber comenzado así el desmoronamiento de la admonición que Touraine, y sus discípulos del Sur, habían hecho pesar sobre los movimientos sociales en América Latina: podrás admitir en tu seno una utopia acerca del fin de la explotación, pero no podrás ejecutar las rupturas políticoinstitucionales que de este 'horizonte' se desprendan.

Touraine prescribió una dosis necesaria de utopía en las acciones colectivas, al tiempo que intentaba dar con la clave para curarla de su locura mesiánica, ergo, totalitaria; la cura ha venido consistiendo, desde hace un tiempo, en justificar el curso regular de la política liberal en crisis advirtiendo tácitamente que, sin explotación, no habría dialéctica ni adversarios para desencadenar la sucesión de sistemas de acción histórica. Podemos ahora sintetizar nuestro análisis en torno de dos elementos fundamentales de la obra de Touraine.

28 Ver Touraine, Alain Actores sociales y sistemas políticos en América Latina, PREALC-OIT, Chile, 1987. Pero, ha sido Manuel A. Garretón quien ha explicitado de forma más clara el marco político de este análisis: "El régimen político tiene, así, por finalidad la resolución de ciertos problemas precisos que toda colectividad debe resolver. El del gobierno: quién y cómo gobierna. El de las relaciones entre la gente y el Estado, es decir, lo que se llama la ciudadanía y la forma como ésta se representa ante el Estado. Finalmente el problema de la canalización de demandas sociales y resolución de los conflictos" Garretón, Manuel A. La sociedad en que vivi(re)mos. Introducción sociológica al cambio de siglo Lom, Santiago de Chile, 2000, p. 93. 
El primer elemento consiste en la morfología que asfixia el cambio social con modelos de fondo invariable. El problema no es la verosimilitud coyuntural de aquel fondo, asegurada por el orden mismo del sistema, sino la pretensión neutro-descriptiva de sus conceptos, de unas palabras que quisieran encontrar así su lugar unívoco, aquel en el que hubiesen estado desde el principio y en el que permanecerían hasta el fin; y que, sin embargo, no cesan de revelar las fuerzas materiales que las hacen funcionar en un discurso sociológico. Al negar la fuerza performadora de los conceptos sobre la historia, Touraine pretende que los suyos son ya la base misma de aquella; así, confunde, o intenta confundir, su precavida voluntad reformadora del capitalismo, con una ciencia de su transformación histórica.

El segundo elemento puede considerarse una derivación metodológica del primero, ya que, cuando se niega la voluntad política que mueve a realizar un determinado análisis, se acrecientan las dificultades para traspasar el marco discursivo en que aquella voluntad ha sido parida. Es así cómo Touraine llega a reconocer con total precisión lo que desea retener, como estructura a la vez plástica e invariable, en su analítica del cambio social. Pero mantiene como punto ciego el anclaje de esta invariabilidad en el pensamiento político liberal de la ilustración eurocéntrica (los "clásicos" como les llama Garretón ${ }^{29}$ ); no es que esconda su credo liberal, sino que, a la sombra de una pretendida distancia científica, extrapola el trozo de historia en que este pensamiento fue formado para convertirlo en estructura necesaria de todas las sociedades con historia. Lo fundamental, para nosotros, radica en constatar que los dos elementos recién señalados, no son el resultado de una intención teórica individual, sino que dan cuenta de un determinado "régimen de enunciación" actualmente operativo en los análisis latinoamericanos que buscan descubrir nuevas formas de acción colectiva en contra de la llamada "globalización neoliberal".

29 Garretón, Manuel A. La sociedad en que ... 
“(...) para que a la mayoría de la gente no avasalle la globalización, hay que tener un Estado [y] un momento en que la gente se representará al Estado, y eso se llama partidos políticos; que sean un desastre o no (...) eso ya es otro problema (...) Lo que sucede actualmente en Brasil es porque se creó un partido (...) Para que la gente no se matara se creó el Estado, y para que el Estado no controlara todo, se crearon los partidos políticos.(...) es el problema que tiene hoy la sociedad civil Argentina, que dice 'que se vayan todos' ¿Qué se vayan todos? ¿Y los reemplace quién? (...) eso lo entendió Chiapas [donde] la primera de las 21 [demandas] era elecciones libres (...) pensemos en el caso boliviano (...) nunca había ocurrido en América Latina que hubiera una mayoría de indígenas en el Parlamento. Eso es porque tomaron en serio la idea de partido, porque tomaron en serio la idea de Parlamento, de Congreso, de democracia burguesa y toda esa cosa. Todo el resto, el basismo, no les creo nada, como tampoco creo en una afirmación solamente del mesianismo político partidario". ${ }^{30}$

Lo notable es que el régimen enunciativo realiza estos llamados a contener las luchas sociales dentro de un marco político único y natural, ${ }^{31}$ con el 'humano' propósito de prevenir que las fiebres utopistas lleguen a cuestionar

30 Garretón, Manuel A. trascripción no revisada por el autor de su intervención en el seminario ONGs y Cooperación Internacional: Los Desafíos del Escenario Actual, Palacio Ariztía, Santiago de Chile, 16 y 17 de enero del 2003.

31 De otra parte, es evidente que la distancia de nuestro discurso con el de Garretón no es más que un impasse en la lengua, una imposibilidad de situar en el lenguaje la justeza de una discrepancia. Así como no debería desconocerse que la perspectiva de Garretón mantiene una importante valoración de la potencia propia de las 'bases sociales'. Lo mismo ocurriría con la nuestra en su relación con el componente organizado, reflexivo y sistemático que robustece la acción social desde la forma orgánica denominada 'partido político'; que además, y según el propio Garretón, perfectamente puede comprender movimientos sociopolíticos como los que se sucedieron en América Latina bajo el influjo de la revolución cubana. La distancia se establece entonces en torno del ¿para qué? de las diversas 'dosis de base y partido-movimiento', remitiéndonos a las hipótesis, intrínsecamente improbables y recíprocamente inconmensurables, de la reforma o de la abolición del capitalismo. 
el pluralismo del pensamiento, pluralismo que queda así recluido en un derecho paradójico (si no miserable) a pensar cualquiera de las alternativas que ya han sido pensadas por la política ilustrada eurocéntrica. ${ }^{32}$ Este es el modo 'inhumano', demiúrgico si se quiere, en que el régimen de enunciación ilustrado satura todas las buenas intenciones del discurso "crítico", es el modo en que enciende sus detectores de "aventurerismo" 33 cada vez que se insinúan formas de acción socialmente autónomas, o sea, dinámicas colectivas que, de manera práctica, -sin tener origen en una siempre improbable conciencia de clase- arruinan la anhelada 'regeneración' de los cauces político-representativos, ejercicios microcolectivizadores de poder intrínsecamente indelegables (anarquía, pre-conciencia, espontaneísmo impolítico, "radicalismo ciego", simple anomia, o la cortedad del ¿y eso... dónde ha formado gobierno?, según las diversas declinaciones del régimen enunciativo). Acorralando estos movimientos en los márgenes discursivos de lo real-constituido es que las ciencias sociales 'críticas' llegan a invocar implícitamente para la superación del neoliberalismo a las mismas fuerzas que lo han actualizado como modo capitalista dominante. Lo que ocurre es que, dentro de este régimen enunciativo, ni siquiera se considera necesario poner en palabras el algoritmo fundacional de la reforma al capitalismo, aquel que supone que la política puede realizar tendencialmente el interés de las mayorías manteniendo una rentabilidad atractiva para las inversiones capitalistas que, de este modo, son aceptadas como el motor natural del bienestar.

32 Pero, Manuel A. Garretón siempre brinda buenos ejemplos de aquel axioma puesto en evidencia por Vicente Huidobro, donde sólo se considera "posible" aquello que es "real" y sólo se considera "real" aquello que es "posible": "Es una ilusión pensar en una sociedad sin leyes. Los anarquistas en un tiempo pensaron esta posibilidad y es a-histórica como lo es el comunismo, como fase última del desarrollo y donde no habrá desigualdades, son imaginarios utópicos, que son inspiradores en términos de horizonte, pero son a-históricos, no existentes. [Hay que buscar] entonces en lo históricamente dado qué posibilidades hay de construir la justicia y la equidad (...)" Garretón, Manuel A., transcripción literal... No es para defender la anarquía o el comunismo, que se denuncia esta fantástica tautología que suele tiranizar el campo sociológico".

33 Ver la entrevista de Touraine concedida a la Revista Hoy (5: septiembre 1991, pp. 32-34) y publicada bajo el sugestivo título "El mundo está cansado de aventuras". 
En este mismo sentido y para los casos en que el discurso crítico se tiene a sí mismo por radicalizado, el régimen enunciativo se confunde con el gesto del marxismo precario que permuta la reflexión acerca de la nueva potencia del trabajo (intelecto, tanto más colectivo, cuanto se realiza de manera cada vez más inmediata en el seno de la sociabilidad) por la confianza en un "nuevo malestar" que la explotación y las desigualdades sembrarían en 'las masas' a las que únicamente haría falta adjuntarles un instrumento partidario que las realizase políticamente. De este modo, -y como con otros fines ha sido puesto en evidencia por Clauss Offe- todo se confía en última instancia, a las capacidades e incapacidades del capital en tanto único motor actual en la creación de valor. ${ }^{34}$

34 Offe plantea que tanto la crítica de derecha como la de izquierda al Estado del Bienestar intentan desconocer el supuesto de las condiciones reales para la rentabilidad del capital como marco en el cual dicho estado cobra sentido, y aunque entre tales condiciones debe contarse -según Offe- la propia acción del Estado, esto puede llegar a ser irrelevante frente a la convicción subjetiva de los capitalistas de que su rentabilidad está siendo institucionalmente restringida. Offe, Claus Contradicciones en el estado del bienestar Alianza, Madrid, 1990. 